\title{
MANAGEMENT OF CONSOLIDATION PROCESSES IN RUSSIA: SOCIAL AND ECONOMIC ASPECTS
}

\author{
Tatiana Ignatova ${ }^{1}$, Antonina Pavlyukova ${ }^{2}$, Lyubov Boldyreva ${ }^{3}$, Svetlana Solonina $^{4}$
}

\begin{abstract}
This article argues that to assess the consolidation of the society and its elite, it is necessary to elaborate mechanisms of national security and the methodological instruments of dialectics. It will allow as the aim of the research attempt to be the determination of the measure and limits of consolidation and reconsolidation, and to find out their essential difference from the integration and reintegration of society. It is shown that the methodology of consolidation analysis of Russian society has its qualitative and quantitative measurements. Qualitative and quantitative assessment of consolidation allows to determine the essence of the category, its modern incarnation, trends of strengthening or weakening, as well as to present mechanisms of national security provision due to a modern stage of development. Consolidation is viewed as a specific case of integration of society and state preferences, society and personal interests, interests of different elites and the state as a whole. The efficiency of the implementation of social development principles depends mostly on the integration of society The principles would adopt differently aimed interests and consolidate platforms of the society.
\end{abstract}

JEL Classification Numbers: A13, B40; DOI: http://dx.doi.org/10.12955/cbup.v6.1156

Keywords: consolidation, reconsolidation, integration, reintegration, social interests, social preferences, social elite

\section{Introduction}

Consolidation or integration of social elite is based on the corresponding processes of consolidation or integration in the society. Recently in scientific research, on expert platforms and forums the consolidation perspective is very often discussed and, in our opinion, it is connected with the current political and economic situation in Russian society. In the conditions of crisis influenced by the decrease in the prices of export resources, the crashes of financial pyramids, specific forms of organization and production are implemented. For example, the international sanctions on Russia and Russia's own retaliatory sanctions as a source of the fastest return on a trajectory of sustainable development become are introduced. The sanctions are consolidated on the purposes and the principles, including international and that of the Eurasian space which will help to overcome difficulties of political settlement, failures of the global and national markets. Border events in Ukraine have negatively influenced the budget and economy of Russia's Rostov region which is one of its biggest territories. Foreign policy and external economic threats returning Russia to unstable growth in the medium term, in general, are too actual, strengthening by the international sanctions, and also keeping threats of destabilization of the situation in South Russia.

For the assessment of consolidation of the society in general and its elites (political, business, scientific, cultural, national, etc.) and the developments of mechanisms of ensuring national security, we suggest using dialectic methodological tools. This will allow for the definition of the measure and the limits of consolidation and reconsolidation so as to reveal her intrinsic differences from integration and reintegration of the society and its elite.

\section{Literature Review}

It is valued in research that concept of consolidation and integration of elite is applied, and described. So, in the resolution of the First elitology congress (October 2013, URI RANEPA, Rostov-on-Don) it was noted that the Congress considers it expedient to recommend to the Russian elite, including intellectual elite, the promotion of the development of the inter-elite relations of CIS countries. Considering the Eurasian priority of foreign policy with Russia, it is expedient to develop a system of elite communications in the former Soviet Union such as lectures by Russian economists, exchange of students, and interaction with teachers of the Russian Slavic universities (Ponedelkov, 2014). Thereby it was recommended to develop various forms of institutionalization of integration of the national elite

\footnotetext{
${ }^{1}$ Department of Economic Theory and Entrepreneurship, Russian Presidential Academy of National Economy and Public Administration University, Moscow, Russian Federation, tignatova@aaanet.ru

${ }^{2}$ Department of Management and Economy of Customs, Russian Customs Academy, Rostov branch, Rostov-naDonu, Russian Federation, bikova_t@list.ru

${ }^{3}$ Department of Economy and Finance, Financial University under the Government of Russian Federation, Krasnodar, Russian Federation, blw75@mail.ru

${ }^{4}$ Department of Economic Security, Kuban State Technological University, Krasnodar, Russian Federation, svevic@mail.ru
} 
in the Eurasian space, including scientific (intellectual) elite by mutual enrichment through exchanging practical experience.

A number of authors substantiate the consolidation of elite groups by indicators of the quality of the elite community, thereby, giving it a discrete character in the course of the analysis of extent of coincidence of opinions and valuable installations of elite community in the Central Federal District: "The analysis of the indexologic profiles of tolerance for various segments of elite community has shown that positions of social and economic elite in many respects coincide and have moderate and negative character; the cultural elite shows a high level of loyalty on a considerable number of indicators, neutrality can be explained with political exclusion; the political elite is distinguished by a coincidence of opinions of both positive, and negative orientation, with domination of the last (to political opponents all manifestations of political activity) are almost banned" (Batanina, Paramonova, 2015).

An important role in the analysis of consolidation is played by the interrelation of the single and the multiple. The category of "consolidation" in scientific literature as opposed to the categories of "fragmentation" of elites, and the description of models of the inter-elite relations relating to such categories as "pact", "community of elite", "convergence of elite" are used by I. V. Shentyakova (2013). At the same time, unity or differentiation as characteristics of elite, in our opinion, have to be applied to a separate type of elite, but not to several elites.

Differentiation of the concepts of consolidation and unity by I. A. Trutnev (2014) is in this regard valuable to the analysis of data of the sociological poll of the political and scientific elite of Primorsky Kray: "The data obtained during the conducted research allow to make a general conclusion that it is rather possible to consider regional elite consolidated (but not rallied), than fragmented. When holding a poll, half of representatives of the political elite and about three-quarters of representatives of the scientific community $(75 \%)$ have characterized the degree of unity of elite groups as average - the main elite groups are poorly consolidated, at the same time, sharp conflicts are absent. Elite groups are poorly consolidated, major political confrontation refers to $25 \%$ of politicians and $10 \%$ of research associates".

The consolidation of elite may happen in case of the disclosure of a leader and elite component of the public life of the region. So, Vorontsov and Ponedelkov (2015) consider that "the new political and economic problems formed by geopolitical opponents of Russia can't be resolved with support from old tools, primary with traditional models of leadership. In the conditions of globalization, not only traditional methods of increasing the efficiency of administrative activity, but also a strategy allowing us to find an optimum way for the achievement of goals with support for earlier not used approaches are necessary without excluding the approaches connected with justified risk, the regional commands of the power". These authors, in our opinion, emphasize the increasing role of leadership of the elite in the conditions of aggravation of constant problems.

The role of integration and consolidation processes in the economic development of Russia is usually viewed through public sector problems (Yakobson, 2000), public choice theory (Nureev, 2005) and in comparison with general socio-dynamics (Grinberg \& Rubinshtein, 2008).

\section{Consolidation Assessment}

It is possible to estimate to what extent modern Russian society is consolidated, using data from sociological polls of VCIOM and other representative polls.

According to weekly polls, (VCIOM) 79-81 percent of the population approve of the activity of the Russian President in June-July, 2016. Yet society is unanimous in assessment of the current economic and foreign policy situation. According to the Levada Center, in the middle of July 2016, the number of Russians recognizing an economic crisis in the country has reached a minimum value for the last six months (77\%) that were below indicators of the beginning of this year (85\%-82\%), but is comparable to indicators for the same period last year. Currently, two-thirds of respondents $(69 \%)$ consider that there is a threat to the security of other countries in the world from the USA, even though a year ago their share was even higher $-77 \%$ (February 2015). On the contrary, $77 \%$ of respondents do not see Russia as a threat for other states. In such a way, the support of the Russian President, the point of the external threat from the USA, recognition of an economic crisis as internal threat society is rather uniform. 
A similar level of estimates can be observed concerning the gravity of threats of terrorism, the need to fight against corruption or crime. Society waits for social justice in providing the state services and distribution of the public benefits. At the same time, it should be noted that also, in quantitative terms, society is consolidated in recognition of the passive engagement in state issues: $73 \%$ of respondents consider that they cannot affect events in the state.

\section{Management of Consolidation: Methodology}

The dialectical approach to the analysis of social development involves the identification of contradictions, of interests of subjects of political and socio-economic relations as the driving force of social development. So the current level of consolidation, in our view, reflects the tendency of the approval of the actors in the ways of realization of their interests in the political field (preference policy of the President of the Russian Federation and, to a lesser extent interest, of the Government of the Russian Federation) and the socio-economic field (prefer social dependency, not the deployment of entrepreneurial initiatives). Quality development concludes in the issue how effective these methods of resolution of contradictions of interests are. In our view, the effectiveness of the implementation of the principles of social development is increasingly tied to the integration of society.

In our opinion, consolidation has to be considered in two aspects: as an independent process and as a quantitatively measured characteristic of opinions and preferences of subjects of a social matrix. Consolidation of society has the quantitative and qualitative measure. Together, quantitative and quality standard of consolidation will allow defining the substantial filling of the category, its current state as a phenomenon, the directions of weakening or strengthening, and offering mechanisms of ensuring national security adequate to the present stage.

If the consolidated society breaks up, then it is necessary to analyze possibilities of a reconsolidation. If the society which is rather consolidated in a quantitative sense demands an exit to a qualitatively new level of development, then it is possible to offer a category of "neo consolidation" as the reply of the consolidated society to the new or amplifying threats. A number of threats are directed to the disintegration of the state and society, and in that case, the analysis of the possible process has to be kept, in our opinion, in the category of "disintegration-integration-reintegration" as the category of "consolidation" can't reflect the entire range of problems of integration.

\section{Managers for Consolidation}

Improving the quality of the business elite and the entire system of management in the business sector largely depends on the skills and training of economists, financiers, accountants, managers, senior executives and middle managers. To achieve high performance, accelerated development of the personnel management and professionals at enterprises and organizations should be adopted. Top managers should have innovative competencies to identify such officers, managers of enterprises turning to the services of the largest universities in the region providing high-quality training of future employees.

Administrative and educational clusters consist in the organization of vocational training and retraining of personnel first of all for bodies of the public and municipal administration and budgetary organizations, but not the enterprises of the national economy. Their specifics distinguish them from the scientific and production and educational clusters created mainly in the sphere of development of production technologies and providing the region with highly qualified specialists of branches. Problems with formation of a reserve of administrative personnel at the national and regional levels have caused an emergence and development of administrative and educational clusters in the south of Russia, formed by the bodies of the state and municipal executive power and institutions of higher professional education.

Scientific, production and educational clusters located in classical and technical universities in the south of Russia are created as in most regions of the Russian Federation. The indisputable leader is the Southern Federal University in Rostov-on-Don. Strong higher education systems supplemented by the innovative centers, business incubators, technological parks have developed in Krasnodar, Volgograd, Vladikavkaz, Stavropol and Pyatigorsk which at the same time provide graduates to the market (Ignatova, 2012).

Administrative-educational clusters in the Russian regions can be created on the basis of cooperation between the Russian Academy of National Economy and Public Administration under the President of 
the Russian Federation, its affiliates, other universities having license for educational programs and special-majoring in public and municipal management, economics and management, law, social work, for personnel services, commissions of personnel policy, centers of retraining and improving the qualifications established by the Executive authorities of the subjects of the Russian Federation and the territorial bodies of the Federal control authorities (e.g. Supervisory, law enforcement), as well as the judiciary.

Joint activities can be carried out on a contractual basis in the exercise of professional retraining and advanced qualified classification of state and municipal employees and the personnel reserve, and in the form of creating Advisory boards in order to harmonize educational programs, identify opportunities and needs for providing places of practice for students, participation of graduates in the contests for the Deputy-absorption positions of the civil service and inclusion in the personnel reserve through the recommendation of the higher educational institutions (Ignatov \& Ignatova, 2013).

In all the universities of the Rostov region preparing specialists for the sector of state and municipal management, which in the future can put the power elite in the region, there is a need to modernize the organizational structures that facilitate employment of graduates in organizations of state and municipal management. The organizational structures should provide the monitoring of their further professional destiny. The structure of the data on potential employees among graduates can be created through the proactive development of student government organizations (student employment service) and through cooperation with the public employment services, personnel services of public authorities and management, public extra-budgetary funds, and local authorities as employers (Zmiyak \& Tyaglov, 2015). A search for organizational forms of realization of services of employment should consider that the establishment of the center of employment is not a self-goal but an instrument of solving problems, which should be socially, economically, and effectively extending the horizon of application of employees in the public sector.

Earlier we have noted that in modern conditions one of the most perspective types of analysis of the interrelation of development of political and economic elite is the institutional analysis. It is based on the consideration of system of norms, rules, customs, their structuring, tracing of influence of institutes on formation of elite, their structure, functions, identification of traps and failures, dependence on the previous way of development, i.e. on presence of proto-elite of a concrete look or transition from one elite to another. Throughout this thesis, it is necessary to explain that the processes of consolidation and integration are considered by us as forms of the institutionalization of all categories of elites unlike forms of an institutionalization of any specific elite. For example, the activities of the Chamber of Commerce and Industry, the Russian Union of Industry and Entrepreneurship, OPORA, the Association of Russian banks, the Association of Russian farmers are various forms of an institutionalization of business elites representing various segments of business: large, average, small, bank, agrarian, etc. The activity of the Public Chamber of the Russian Federation is an example of the integration of the elite: imperious, economic, cultural, scientific, national.

In this regard, it should be noted that the understanding of consolidation of social elite of Ponomarenko (2013) represents other systems of coordinates of scientific research: "The period of consolidation is the third stage elitogenesis preceded by the process of crushing and an institutionalization of political elite. Groups of political elite that saved up bigger quantity of resources at a stage of "crushing" in the period of "institutionalization" preserve the developed system of the imperious relations within a certain political regime at the stage of "consolidations", having received a monopoly for the definition of "rules of the game" in political process". We prefer to consider the process of institutionalization as a constant for each stage of elitogenesis and the formation of the structure of the political elite, and the "stabilization of its structure in the conditions of consolidation" proceeding in a certain institutional framework, both in formal or, most often, in informal rules and norms. Unless it is elitogenesis, it is dialectically doomed to split or disintegrate the elite at late stages of its development.

\section{Conclusion}

These methodological problems, in our view, have considerable potential for analysis to develop measures to strengthen the economic and national security of the Russian Federation. The deformation of a modern market under international sanctions and Russian counter-sanctions affects the Russian 
society, which supports in the long-term import substitution and technological breakthrough and does not expect fast growth of standard of living (Ryabova \& Ignatova, 2016). The difficult economic and political situation is recognized by elites too. Therefore, the task of the state in the short and medium term is, in our opinion, not to strengthen consolidation (to increase the level of consolidation, reflecting the share of convergence, but to prevent disintegration and to maintain the integration of society and its elites at the existing level.

We suggest considering consolidation as a special case of integration at meeting both public and state preferences, public and personal interests, the interests of various elites to the interests of the state in general. Whereas integration assumes a wide range of balances and compromises, ways of resolution of conflicts of interests of individuals, society and its elite, collectives, the organizations, social groups, power structures of the regions and other private and integrated subjects of a social matrix aimed at maintenance of sustainable development and national security.

\section{References}

Batanina I. A., Paramonova O. V. (2015) Features of consolidation of regional elite. News of Tula state university. Humanities. 4: 34.

Grinberg R.S., Rubinshtejn A.YA. (2008) Basics of mixed economy. Ecosocial dynamics. Moscow, IEH RAN: 480.

Zmiyak S. S., Tyaglov S.G. (2015) Quality management of training of skilled workers as key problem of interaction of labor market and education market. Journal of Economic Regulation. 6: 2-8.

Ignatov V. G., Ignatova T. V. (2013) Interaction of the state and business in the South of Russia: expert estimates and postcrisis regulation. KBSC RAN News. 1: 6.

Ignatova T. V. (2012) Formation of an administrative reserve of the region through development of administrative and educational clusters. Creative economy. 3: 95.

Nureev P.M. (2005) Public choice theory. Course of lectures. Moscow: State University - High school of Economics: 531.

Ponedelkov A. V. (2014) Political elite of Russia: current state and prospects of modernization. Public and municipal administration. Scientific notes of SKAGS. 1.

Ponomarenko N. A. (2013) Features and mechanisms of "consolidation" of political elite in Post-Soviet Russia. European Social Science Journal. 11-2 (38): 481-483.

Ryabova T. F., Ignatova T. V. (2016) Mechanism of national economic security on the basis of formation of market conditions. Food industry. 5: 24.

Shentyakova A. V. (2013) Possibilities of consolidation of elite in pre-election the period. Political expertise: POLITEX. 9: 4-98.

Trutnev I. A. (2014) Political elite of Primorsky Krai: values and level of consolidation. Bulletin of Baikal state university. 1: 61-73.

Vorontsov S.A., Ponedelkov A. V. (2015) Leader and elite component of modern Russian political management at the regional level. Public and municipal administration. Scientific notes of SKAGS. 1: 136.

Yakobson L.I. (2000) Public sector of economy/ Economic theory and policy. Moscow: State University - High school of Economics: 369 . 